\title{
Pemantauan Kondisi Kepadatan Jalan Kelurahan Sawojajar dengan menggunakan Image Processing Berbasis Visual Basic 6.0
}

\author{
Kholilatul Wardani, Aditya Kurniawan \\ Politeknik Kota Malang \\ Kompleks Pendidikan Internasional Tlogowaru No 3, telp/fax (0341) 754088 \\ e-mail: kholilatulwardani@gmail.com
}

\begin{abstract}
Abstrak - Pada penelitian ini dibuat suatu implementasi sistem transportasi cerdas dalam manajemen trafik di perempatan jalan menggunakan compiler visual basic 6.0. Sistem ini menjadikan kamera sebagai alat pemantau yang dipasang sebagai sensor kepadatan jalan. Hasil yang ditangkap oleh kamera akan diproses menggunakan algoritma image processing, untuk dapat menghitung jumlah mobil yang terekam. Dari jumlah mobil yang didapatkan dapat mennjukkan status kepadatan jalan.

Akurasi dari analisa pendeteksian jumlah kendaraan pada kondisi jalan sepi/lengang 100\%, kondisi jalan ramai tapi tidak padat dengan akurasi sebesar 97,06\% dan kondisi jalan padat dengan akurasi sebesar $92,06 \%$.
\end{abstract}

Kata kunci: visual basic 6.0, kamera, kepadatan jalan

\section{Pendahuluan}

Salah satu permasalahan dalam bidang lingkungan adalah lalu lintas, dimana lalu lintas menjadi aspek yang dapat diperhitungkan dalam sebuah sistem perekonomian baik menguntungkan dan merugikan bagi masyarakat. Sebuah lalu lintas yang baik dapat mendatangkan keuntungan, dan lalu lintas yang buruk dapat mendatangkan kerugian. Lalu lintas tentu berhubungan dengan jumlah alat transportasi, pergerakan alat transportasi, dan komponenkomponen lain yang mendukung transportasi itu sendiri, seperti jalan, lampu lalu lintas, rambu lalu lintas dan pengguna lalu lintas.

Peningkatan jumlah kendaraan yang terus bertambah, serta tuntutan mobilitas yang tinggi, lancar dan aman menuntut suatu sistem transportasi yang baik dan efisien. Mobilitas yang tinggi dapat membuat lalu lintas menjadi terganggu, sehingga memperlambat mobilitas yang terjadi, atau sering disebut dengan kemacetan. Kemacetan bisa terjadi dikarenakan beberapa hal, contohnya adalah kecelakaan, kerusakan sistem kendaraan, dll.

Kemacetan lalu lintas sudah merupakan kegiatan rutin yang kita hadapi sehari-hari. Bahkan seperti yang telah dikatakan sebelumnya, hal tersebut menunjukkan potensi kerugian yang sangat besar dari kondisi tersebut. Karenanya, berbagai upaya harus segera dilakukan untuk mengatasi masalah ini karena jika masalah tidak ditangani segera, maka akan menyebabkan deadlock dalam waktu yang tidak lama lagi. Banyak yang beranggapan bahwa untuk memperbaiki permasalahan tersebut hanya bergantung pada pembangunan jalan baru atau perbaikan infrastruktur dengan aspal, beton dan besi. Padahal perbaikan dapat dilakukan secara signifikan dengan peningkatan melalui penerapan teknologi informasi dan komunikasi secara luas pada sistem transportasi.

Teknologi informasi dan komunikasi memungkinkan komponen-komponen pendukung transportasi menjadi sistem yang dapat bekerja secara 'pintar' berdasarkan informasi informasi yang telah diberikan dahulu terhadap sistem tersebut dan sistem tersebut dapat mempelajarinya, atau yang lebih familiar dengan sebutan artificial intelligence system. Dengan

TELKA, Vol.2, No.1, Mei 2016, pp. 62 69

ISSN: 2502-1982 
memanfaatkan teknologi tersebut dalam aplikasi sistem transportasi dapat disebut dengan sistem transportasi cerdas atau Intelligent Transport System (ITS)[4].

Sistem transportasi cerdas memiliki banyak bagian utama yang dapat dikembangkan. Antara lain dari sisi pengguna, pusat sistem transportasi cerdas, alat transportasi dan jalan raya[4]. Pada tahap awal, sistem transportasi cerdas akan difokuskan pada aplikasi manajemen trafik lalu lintas serta layanan informasi lalu lintas. Sistem ini berbasis computer vision dan komunikasi yang mampu mengekstraksi data penting dari kamera dalam proses monitoring, sehingga secara cerdas dan mandiri mampu mengirimkan informasi dan notifikasi pada pihak yang berkepentingan. Selain dari proses monitoring, banyak informasi yang dapat diolah oleh sistem transportasi cerdas, anatar lain pemberian sesnsor pada kendaraan, administrasi dan otomatisasi untuk manajemen trafik, notifikasi untuk pengguna, sehingga pada saat keseluruhan elemen tersebut saling berintegrasi, maka akan dapat menghasilkan suatu sistem transportasi cerdas yang akan membantu mengatasi permasalahan lalu lintas yang akan sangat berguna bagi banyak pihak.

\section{Metodologi Penelitian}

Dalam penelitian ini akan memanfaatkan beberapa teknik dalam pengolahan citra digital. Teknik-teknik tersebut akan disusun sehingga dapat membentuk algoritma yang dapat digunakan untuk implementasi sistem transportasi cerdas. Teknik pengolahan citra yang digunakan antara lain colour extraction, Image-Enhancement, yang meliputi brightness dan contrast, colour filtering dan object detection ${ }^{[15]}$.

Suatu citra digital berwarna terdiri dari tiga kanal warna dasar: merah, hijau, serta biru. Pemodelan seperti ini disebut dengan model RGB (red, green, blue). Jika setiap piksel memerlukan 8 bit untuk menyatakan tingkat keabuan per kanalnya, maka total bit yang diperlukan untuk merepresentasikan nilai warna di tiap pixelnya adalah 24bit. Walaupun demikian, kebanyakan citra berwarna 24-bit adalah 32-bit, dengan 8 bit ekstra digunakan untuk menyatakan tingkat alpha. Hampir setiap pengolahan citra yang berbasis warna perlu dilakukan pemisahan band-band yang ada pada citra khususnya citra $\mathrm{RGB}^{[15]}$.

Algoritma untuk memisahkan warna dari suatu citra ke dalam 3 komponen RGB, adalah :

$$
\begin{aligned}
& \mathrm{P}(\mathrm{i}, \mathrm{j}) \quad=\text { data mentah pixel pada baris i colom } \mathrm{j} \\
& R_{0}(i, j)=\text { nilai warna merah yang diekstrak dari } \mathrm{P}(\mathrm{i}, \mathrm{j}) \\
& G_{0}(i, j)=\text { nilai warna hijau yang diekstrak dari } \mathrm{P}(\mathrm{i}, \mathrm{j}) \\
& B_{0}(i, j)=\text { nilai warna biru yang diekstrak dari } \mathrm{P}(\mathrm{i}, \mathrm{j}) \\
& P_{0}(i, j)=\text { RGB Colour format pada baris i kolom } \mathrm{j} \\
& P_{0}(i, j)=\left(R_{0}(i, j), G_{0}(i, j), B_{0}(i, j)\right) \\
& P_{0}(i, j)=\left(\left(P(i, j) \bmod 2^{16}\right) \bmod 2^{8}, \frac{P(i, j) \bmod 2^{16}}{2^{8}}, \frac{P(i, j)}{2^{16}}\right)
\end{aligned}
$$

Image enhancement atau bisa disebut dengan perbaikan kualitas citra gambar adalah proses mendapatkan citra gambar yang lebih mudah diinterpretasikan oleh mata manusia. Perbaikan kualitas citra (image enhancement) pada dasarnya adalah manipulasi, yang dilakukan pada sebuah citra untuk suatu keperluan yang spesifik, dengan memanfaatkan aspek-aspek sistim penglihatan manusia. Pemilihan teknik yang digunakan harus sesuai dengan jenis citra dan tujuan yang diharapkan. Tujuan utama perbaikan suatu gambar adalah untuk memproses sebuah gambar yang hasilnya dapat lebih berguna dari gambar aslinya untuk aplikasi tertentu. Pada proses ini, ciri-ciri tertentu yang terdapat didalam citra lebih diperjelas kemunculannya. 
Image enhancement terbagi dalam 2 kategori, yaitu metode spatial domain dan metode frequency domain. Spatial domain berkenaan dengan ruang gambar itu sendiri, dan berdasarkan manipulasi langsung pixel- pixel dari gambar. Frequency domain didasarkan pada modifikasi transformasi Fourier pada gambar. Image enhancement digunakan untuk memperbaiki kualitas image, seperti sharpening(penajaman) dan perbaikan brightness, contrast.

Rumusan untuk operasi brightness enhancement (autobrightness), adalah :

$$
\begin{aligned}
& \operatorname{Gray}_{(x, y)}=\frac{\left(\left(\left\langle\mathrm{P}_{(z, y)} \operatorname{MOD}\left(2^{16}\right)\right\rangle \operatorname{MOD}\left(2^{\mathrm{a}}\right)\right)+\left(\operatorname{Int}\left(\frac{\left\langle\mathrm{P}_{(z, z)} \operatorname{MOD}\left(2^{16}\right)\right\rangle}{\left(2^{\mathrm{s}}\right)}\right)\right)+\left(\operatorname{Int}\left\langle\frac{\mathrm{P}_{(z, y)}}{2^{16}}\right\rangle\right)\right)}{3} \\
& \mathrm{~Kb}=\mathrm{Tb}-\frac{1}{P w x P h} x \sum_{y=1}^{P h} \sum_{x=1}^{P w} \operatorname{Gray}_{(x, y)}
\end{aligned}
$$

Algoritma umum auto brightness

$$
\mathbf{K b}=\mathbf{T b}-\frac{1}{P \boldsymbol{w} \times \boldsymbol{P h}} x \sum_{y=1}^{P h} \sum_{x=1}^{P \boldsymbol{w}} \frac{\left(\left(\left\langle\mathrm{P}_{(x, y)} \operatorname{MOD}\left(2^{16}\right)\right\} \operatorname{MOD}\left(2^{3}\right)\right)+\left(\operatorname{Int}\left(\frac{\left\langle\mathrm{P}_{(z, y)} \operatorname{MOD}\left(2^{16}\right)\right\rangle}{\left(2^{\mathrm{s}}\right)}\right)\right)+\left(\operatorname{Int}\left\langle\frac{\mathrm{P}_{(z, y)}}{2^{16}}\right\rangle\right)\right)}{3}
$$

Dimana :

Kb adalah nilai koeffisien brighness (nilainya -255 s/d 255)

$\operatorname{Gray}_{(x, y)}$ adalah nilai grayscale dari sebuah pixel (nilainya 0 s/d 255)

Tb adalah nilai threshold brightness (nilainya $80 \mathrm{~s} / \mathrm{d} 120)$

Pw adalah banyaknya pixel dalam garis horizontal (Picture Width)

Ph adalah banyaknya pixel dalam garis vertical (Picture Height).

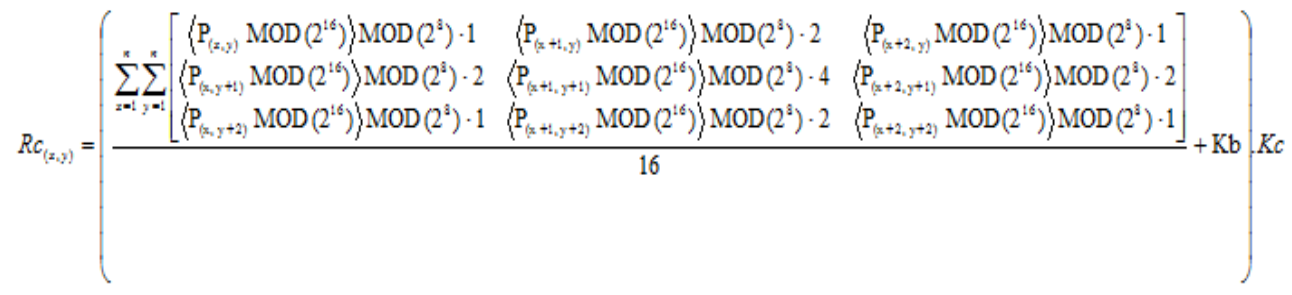

Dimana :

$\boldsymbol{R c}_{(\mathbf{x}, \mathbf{y})}$ adalah Nilai contras warna merah pada kolom $\mathrm{x}$, baris $\mathrm{y}$

$\mathbf{P}$ adalah Value Image pada pixel (Raw data)

MOD adalah Modulus

Kb adalah Koefisien brightness (-255 - 255)

Kc adalah Koefisien contrast $(0,1-1,9)$

Jika $0<\mathrm{Kc}<1$ maka akan mengurangi kekontrasan suatu warna.

Jika $1<\mathrm{Kc}<2$ maka menambah kekontrasan suatu warna.

Filtering adalah suatu proses dimana diambil sebagian sinyal dari frekwensi tertentu, dan membuang sinyal pada frekwensi yang lain. Filtering pada citra juga menggunakan prinsip yang sama, yaitu mengambil fungsi citra pada frekwensi-frekwensi tertentu dan membuang fungsi citra pada frekwensi-frekwensi tertentu.

Dari sifat-sifat citra pada bidang frekwensi, maka prinsip-prinsip filtering dapat dikembangkan adalah sebagai berikut: 
a. Bila ingin mempertahankan gradiasi atau banyaknya level warna pada suatu citra, maka yang dipertahankan adalah frekwensi rendah dan frekwensi tinggi dapat dibuang atau dinamakan dengan Low Pass Filter. Hal ini banyak digunakan untuk reduksi noise dan proses blur.

b. Bila ingin mendapatkan threshold atau citra biner yang menunjukkan bentuk suatu gambar maka frekwensi tinggi dipertahankan dan frekwensi rendah dibuang atau dinamakan dengan High Pass Filter. Hal ini banyak digunakan untuk menentukan garis tepi (edge) atau sketsa dari citra.

c. Bila ingin mempertahankan gradiasi dan bentuk, dengan tetap mengurangi banyaknya bidang frekwensi (bandwidth) dan membuang sinyal yang tidak perlu maka frekwensi rendah dan frekwensi tinggi dipertahankan, sedangkan frekwensi tengahan dibuang atau dinamakan dengan Band Stop Filter. Teknik yang dikembangkan dengan menggunakan Wavelet Transform yang banyak digunakan untuk kompresi, restorasi dan denoising.

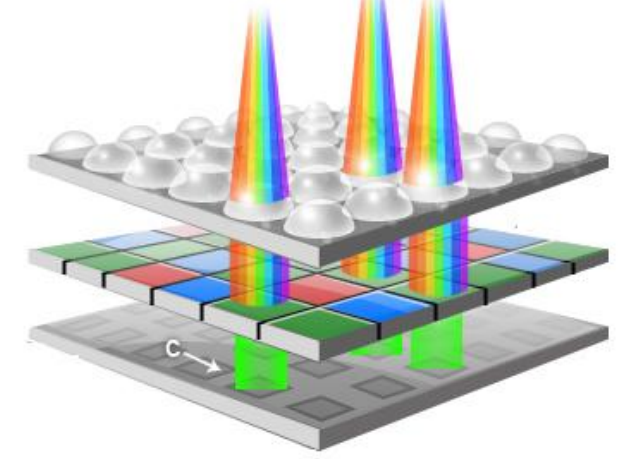

Gambar 1. Proses filtering komponen warna

Rumus umum R filtering (Rf), G filtering (Gf), dan B filtering (Bf) seperti dibawah ini :

$$
\left(\mathrm{Rf}_{(x, y)}, \mathrm{Gf}_{(x, y)}, \mathrm{Bf}_{(x, y)}\right)=\left(\begin{array}{l}
\left\{\mathrm{Rc}_{(x, y)} \in N:\left(R_{t h}-\text { Bandwidth }\right) \geq \mathrm{Rc}_{(x, y)} \geq\left(R_{t h}+\text { Bandwidth }\right)\right\}_{,} \\
\left\{\mathrm{Gc}_{(x, y)} \in N:\left(G_{t h}-\text { Bandwidth }\right) \geq \mathrm{Gc}_{(x, y)} \geq\left(G_{t h}+\text { Bandwidth }\right)\right\}_{2} \\
\left\{\operatorname{Bc}_{(x, y)} \in N:\left(B_{t h}-\text { Bandwidth }\right) \geq \mathrm{Bc}_{(x, y)} \geq\left(B_{t h}+\text { Bandwidth }\right)\right\}
\end{array}\right),
$$

Dimana:

$\mathbf{R f}_{(\mathbf{x}, \mathbf{y})}$ adalah Warna merah pada kolom $\mathrm{x}$, baris y yang sudah difiltering

$\mathbf{G f}_{(\mathbf{x}, \mathbf{y})}$ adalah Warna hijau pada kolom $\mathrm{x}$, baris y yang sudah difiltering

$\mathbf{B f}_{(\mathbf{x}, \mathbf{y})}$ adalah Warna biru pada kolom $\mathrm{x}$, baris y yang sudah difiltering

$\mathbf{R c}_{(\mathbf{x}, \mathbf{y})}$ adalah Nilai contrast warna merah pada kolom $\mathrm{x}$, baris $\mathrm{y}$

$\mathbf{G c}_{(\mathbf{x}, \mathbf{y})}$ adalah Nilai contrast warna hijau pada kolom $\mathrm{x}$, baris $\mathrm{y}$

$\mathbf{B} \mathbf{c}_{(\mathbf{x}, \mathbf{y})}$ adalah Nilai contrast warna biru pada kolom $\mathrm{x}$, baris $\mathrm{y}$

$\mathbf{R}_{\text {th }}$ adalah Ambang batas (threshold) nilai warna merah

$\mathbf{G}_{\text {th }}$ adalah Ambang batas (threshold) nilai warna hijau

$\mathbf{B}_{\text {th }}$ adalah Ambang batas (threshold) nilai warna biru

Bandwidth adalah Area varian nilai warna yang diinginkan

Pendeteksian objek dapat dilakukan dengan mendeteksi tepi dari suatu objek. Deteksi Tepi ( Edge Detection ) pada suatu citra atau image adalah suatu proses yang menghasilkan tepi-tepi dari obyek-obyek gambar. Suatu titik (x,y) dikatakan suatu sebagai tepi (edge) suatu citra apabila titik tersebut memiliki perbedaan yang tinggi dengan sekitarnya, seperti terlihat pada gambar. Hasil perhitungan apabila lebih besar daripada ambang batas (threshold) maka pixel tersebut merupakan edge (garis tepi) suatu citra ( perhitungan $>$ threshold $=0$ ), sebaliknya jika hasil perhitungan lebih kecil daripada ambang batas (threshold) maka pixel tersebut bukan merupakan edge(garis tepi) dimana perhitungan $<$ threshold $=255$. 


\begin{tabular}{cc}
\multicolumn{2}{c}{ Table 1. Variabel penelitian } \\
\hline $\begin{array}{c}\text { Variabel } \\
\text { independen }\end{array}$ & $\begin{array}{c}\text { Variabel } \\
\text { dependen }\end{array}$ \\
\hline Pixel & $\begin{array}{c}\text { Kepadatan } \\
\text { jalan }\end{array}$ \\
\hline
\end{tabular}

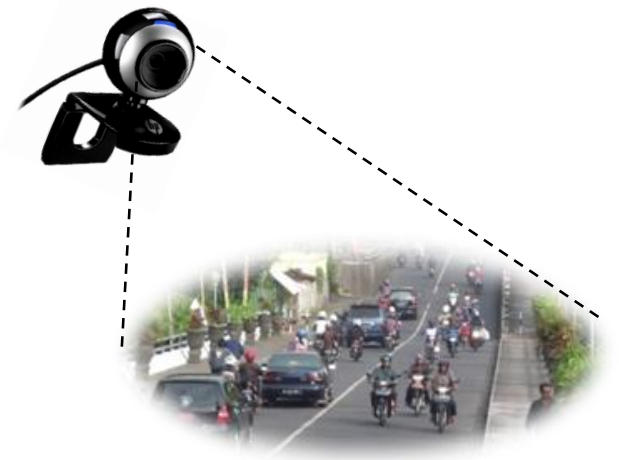

Gambar 2. Setup penelitian

\section{Results and Analysis}

\subsection{Pengujian Pengolahan Citra}

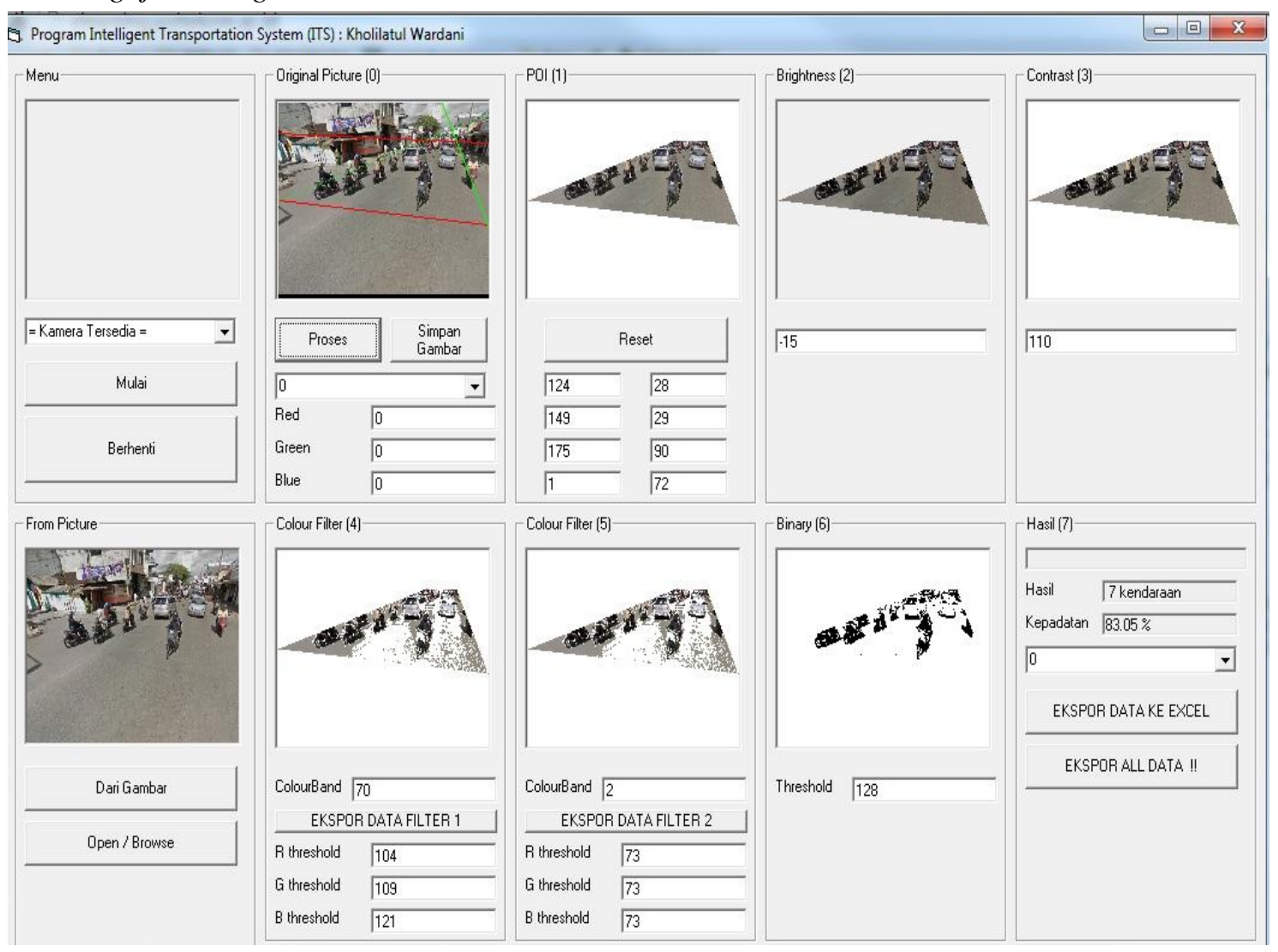

Gambar 3. Software pengolahan citra 


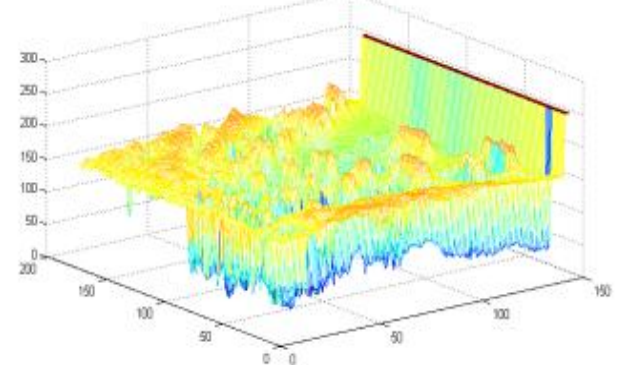

Colour Extraction

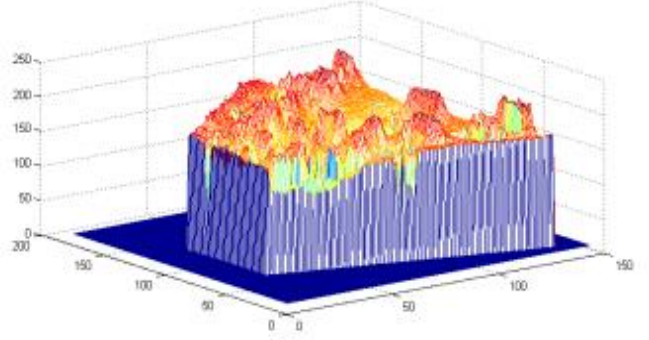

Image Enhancement

(Brightness)

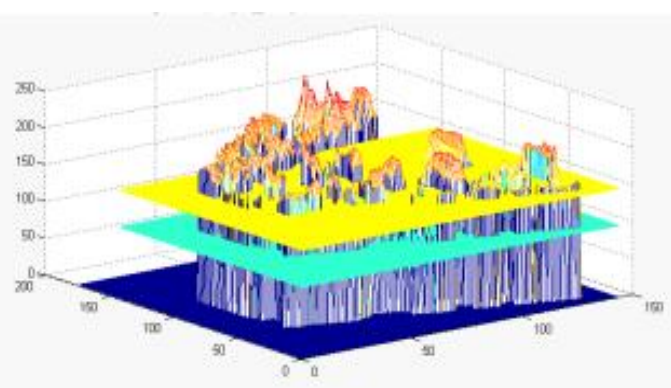

Colour Filtering-1

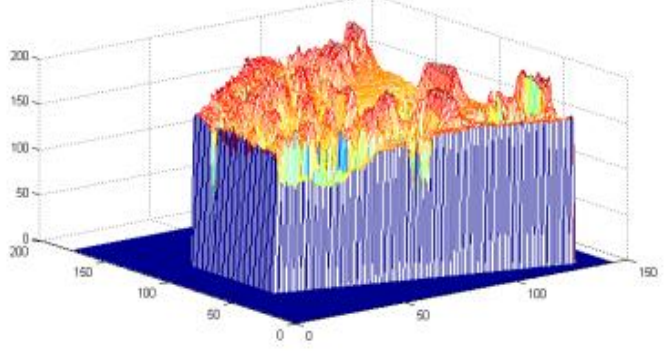

Point of Interest

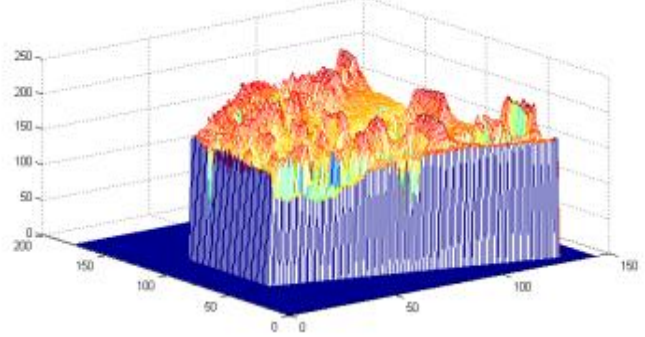

Image Enhancement

(Contrast)

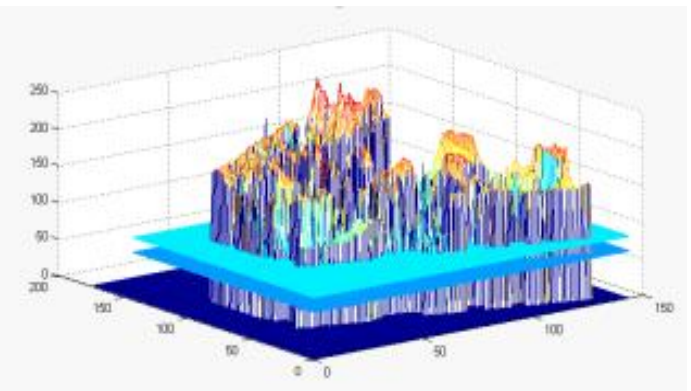

Colour Filtering-2

Gambar 4. Grafik Analisa proses pengolahan citra menggunakan MATLAB

Untuk pengujian akurasi deteksi kendaraan, parameter yang akan diamati adalah tingkat keakurasian dan error deteksi, sehingga dapat mengetahui kehandalan algoritma yang digunakan dalam proses pendeteksian. Pengujian ini dilakukan untuk beberapa kondisi yang berbeda, seperti dalam kondisi sepi, lancar dan padat.

Pada saat pengujian ada beberapa parameter yang dijadikan sebagai nilai threshold, yang didapatkan dari beberapa kali pengujian. Dari beberapa kali pengujian tersebut akan didapatkan nilai yang paling cocok untuk diaplikasikan dalam pendeteksian objek. Nilai threshold yang sesuai akan dijadikan sebagai nilai parameter kunci dalam pengujian selanjutnya. Parameterparameter tersebut antara lain :

Tabel 2. Parameter hasil training set

\begin{tabular}{|c|c|}
\hline Parameter & $\begin{array}{c}\text { Nilai } \\
\text { threshold }\end{array}$ \\
\hline Brightness & -15 \\
\hline Contrast & 110 \\
\hline
\end{tabular}




\begin{tabular}{|c|c|}
\hline Parameter & $\begin{array}{c}\text { Nilai } \\
\text { threshold }\end{array}$ \\
\hline $\begin{array}{c}\text { Colour band filtering- } \\
1\end{array}$ & 50 \\
\hline $\begin{array}{c}\text { Colour band filtering- } \\
2\end{array}$ & 20 \\
\hline Binary conversion & 128 \\
\hline
\end{tabular}

Tabel 3. Hasil pengujian akurasi deteksi kendaraan

\begin{tabular}{|c|c|c|c|c|c|c|}
\hline No & Terdeteks & Sebenamya & Kondisi & Error & Akurasi & Gambar \\
\hline 1 & 1 & 1 & Lancar & $0,00 \%$ & $100,00 \%$ & 4 \\
\hline 2 & 2 & 2 & Lancar & $0,00 \%$ & $100,00 \%$ & 7 \\
\hline 3 & 3 & 3 & Lancar & $0,00 \%$ & $100,00 \%$ & 1 \\
\hline 4 & 4 & 4 & Lancar & $0,00 \%$ & $100,00 \%$ & 5 \\
\hline 5 & 4 & 4 & Lancar & $0,00 \%$ & $100,00 \%$ & 12 \\
\hline 6 & 4 & 4 & Lancar & $0,00 \%$ & $100,00 \%$ & 13 \\
\hline 7 & 7 & 7 & Lancar & $0,00 \%$ & $100,00 \%$ & 11 \\
\hline 8 & 10 & 10 & Lancar & $0,00 \%$ & $100,00 \%$ & 10 \\
\hline 9 & 18 & 18 & Lancar & $0,00 \%$ & $100,00 \%$ & tes \\
\hline 10 & 19 & 17 & Lancar & $11,76 \%$ & $88,24 \%$ & 17 \\
\hline 11 & 35 & 37 & Padat & $5,41 \%$ & $94,59 \%$ & padat1 \\
\hline 12 & 34 & 38 & Padat & $10,53 \%$ & $89,47 \%$ & padat2 2 \\
\hline 13 & 33 & 37 & Padat & $10,81 \%$ & $89,19 \%$ & padat 3 \\
\hline 14 & 38 & 40 & Padat & $5,00 \%$ & $95,00 \%$ & padat4 \\
\hline & \multirow{3}{*}{\multicolumn{2}{|c|}{ Rata-Rata }} & Sepi & $0,00 \%$ & $100,00 \%$ & \\
\hline & & & Lancar & $2,94 \%$ & $97,06 \%$ & \\
\hline & & & Padat & $7,94 \%$ & $92,06 \%$ & \\
\hline
\end{tabular}

\section{Kesimpulan}

Sistem mampu melakukan kalkulasi kepadatan jalan berdasarkan hasil kalkulasi penghitungan jumlah kendaraan, dalam periode waktu pengamatan yang ditentukan. Penentuan status kepadatan berdasarkan perbandingan prosentase perbandingan antara objek mobil yang terdeteksi dengan luas jalan. Dari perbandingan tersebut diklasifikan dalam 2 kondisi, yaitu : prosentase $<50 \%$ klasifikasi kondisi lancar, dan prosentase $\geq 50 \%$ klasifikasi kondisi padat. Perhitungan volume kendaraan dengan akurasi pada kondisi jalan sepi/lengang 100\%, kondisi jalan ramai tapi tidak padat dengan akurasi sebesar $97,06 \%$ dan kondisi jalan padat dengan akurasi sebesar $92,06 \%$, masih diperlukan perbaikan agar dapat meningkatkan keakurasian. Keakurasian yang berbeda disebabkan adanya perbedaan tingkat iluminasi pada latar belakang objek.

Penelitian ini secara keseluruhan belum secara lengkap membuat sistem transportasi cerdas yang diperlukan. Masih perlu dilakukan optimasi algoritma image processing sehingga dapat meningkatkan keakurasian dengan pemrosesan dalam kondisi real time.

Secara singkat dapat disimpulkan bahwa (1) kepadatan jalan berbanding lurus dengan jumlah pixel gelap (hitam) RGB 0,0,0 dan (2) Algoritma colour filter sangat bergantung pada variasi warna dan iluminasi pada objek

\section{Daftar Pustaka}

[1] Atkociunas, E. et al, Image Processing in Road Traffic Analysis, Proc. Nonlinear Analysis: Modeling and Control, 2005;10:312-332.

[2] Choe, T., Lee, M. W., Haering, N., Traffic Analysis with Low Frame Rate Camera Networks, Object Video Inc, IEEE Conference Publishing,USA.2010.

[3] Hendrawan, Penelitian Tesis S2, Pengembangan Testbed Intelligent Transport System untuk Manajemen Trafik Lalulintas. STEI ITB, Bandung. 2013

[4] Intachak, T., Kaewapichai, W., IEEE Conference Publishing, Real-Time Illumination Feedback System for adaptive background substraction working in traffic video monitoring, Songkla University, Thailand. 2011 
[5] Jain, A, Fundamentals of Digital Image Processing, Prentice-Hall, Englewood Cliffs, NJ.1986

[6] Malhi, M. H., Aslam, M. H., Saeed, F., Javed, O., Fraz, M., IEEE Conference Publishing, Vision Based Intelligent Traffic Management System, Institute of Information Technology, Lahore. 2011

[7] Peter Hamonangan L. Tobing, "Aplikasi Video Processing pada Server untuk Sistem Pemantauan dan Analisis Trafik Kendaraan di Jalan Tol," Institut Teknologi Bandung, Bandung. 2010

[8] Rafael C. Gonzales and Richard E. Woods, Digital Image Processing, 3rd ed. Pearson.New Jersey.2010.

[9] Russ, J. C, The Image Processing Handbook, Prentice-Hall, Upper Saddle River, NJ, Edisi 7.1998 